\title{
JOKE, LAUGH AND CRY: QUALITATIVE ANALYSIS OF “MEME” IN PSYCHODYNAMICS AND COLLECTIVE PSYCHIATRIC CLINIC
}

\author{
Santos, Arthur D. Chaves. \\ Universidade Anhembi Morumbi. Brazil. \\ School of Medical Science at Piracicaba. \\ arthur.chaves@unesp.br
}

\begin{abstract}
Existing is a verb that encompasses basal biological categories - biochemical, cellular and molecular processes - and psychodynamics, these tied to the experiences of ones and the world. Mental health, then, has as essential problem the face of the other and the "Other" through limited mechanisms and, also, by affections marked by otherness. The question, therefore, was "the most viral memes are based on which psychic processes and, therefore, what was the related otherness?". Three Accounts on Instagram - @jedinizm, @pacifylyrics and @mariamchami - were evaluated qualitatively based on the parameters (i) communication objective, (ii) particular psychic function made collective and (iii) taboos and restrictive social norms addressed; clash arose by the critical reading of Sigmund Freud and Maria Homem. The joke was observed in the three accounts, @pacifylyrics presented greater conjugation between images - individual memes - and songs, @mariamchami, in turn, acts in a disruptive way, demystifying the image of the muslim woman through the ridicule of the intolerant thinking of the viewer. @jedinizm, more attentive to the public in general, brings themes such asadultery and financial bankruptcy as objects of laughter and subversion. In all cases, the meme acted as elaboration of affections for conscious denial, raising the characteristic austerity of forbidden themes in the social norm. It is, in fact, a category of popular education in collective mental health.
\end{abstract}

Keywords: meme; psychiatry; collective health; popular health education; psychodynamic.

\section{INTRODUCTION}

Observing the surroundings and oneself is the teleological task of the psychic apparatus, having through mechanisms of affection and symptom directed directly or 
indirectly to the object. It would be, however, simple to establish a relationship of cause and objective effect between the surroundings and the subjective reaction of the individual. The intricacies and subversions of reality act, in fact, as softening and substitution reactions before the intolerable for themselves or, still, for the collective.

It is in this perspective of an always collective mental health that the present work arises. The meme, as a new category, emerges a current and innovative psychodynamic artifice regarding the reactivity of the individual, collectively, to taboos and the protection of the ridicule of oneanother.

Politics, dignity and psychodynamics are an amalgam in the era of Instagram and TikTok. The question outlined, therefore, is whether there is efficacy in communication through memes, or whether it is capable of intervening in psychodynamics.

\section{METHOD AND BIBLIOGRAPHIC REVIEW}

Science does not thrive in orthodoxy. Thus, cut from June 2020 to July 2021, the profiles on Instagram@jedinizm, @pacifylyrics and @mariamchami were qualitatively analyzed, with the confrontation of the findings - feed, reels and stories - by the assertions of Freud and Maria Homem regarding the pedagogical psychopathologyand the place of the joke in psychodynamics. In Freud, the joke already emerges as an intrinsic relationship with the inconscious; discourse and ich partum coexists. Maria Homem, contemporary, investigates the ridicule, cringe and taboo through the perspective of the meme; "[the] meme is also a defense for the tragic. Before I get ridiculous, I make the laugh."

\section{FINDINGS}

The results of the proposed analyses follow: @pacifylyrics presented greater conjugation between images - individual memes - and songs, forming, a larger and one meme, further sharpening the experience of laughter in the face of the disgrace of frustrated passion and depressive and anxious symptoms. @mariamchami, in turn, acts in a disruptive way, demystifying theimage of muslim women through the ridicule of the intolerant thinkingof the viewer; instills values of self-criticism and religious tolerance by exploiting ridicule. 
@jedinizm, more attentive to the general public, brings themes such as adultery and financial failure as objects of laughter and subversion.

\section{CONCLUSION}

In the cases, the meme acted as elaboration of affections by conscious denial, raising - or reducing tension on - the austerity characteristic of themes prohibited in the social norm. It is, in fact, a category of popular education in mental health witholetiva.

\section{DISCUSSION}

The rules are built on a fundamental norm. Depending on the theoretical current, the impossibility of all saying or the prohibition of incest are the basis of all other taboos. The meme, in this way, would be limited to the most superficial prohibitions.

On theother hand, they destabilize the status quo, an action whose consequence is alwaysunexpected. More accurate studies should investigate memetic communication and its relationship with the strengthening of taboos. The rebound effect was never denied. The limit of laughing with the other, according to Maria Homem, is tenuous before the laughter of the other.

\section{REFERENCES}

1. Freud, S. The jokes and their relationship with the unconscious [1905]. In: Brazilian standard edition of complete psychological works. RJ: Imago, 1980. v. VIII.

2. Meme? [Internet]. Brazil; 2021 Aug 13. Meme?; [cited 2021 Aug 14]; Available from: https://www.youtube.com/watch?v=ti8-kvF3AT8 